\title{
GLOBAL-LOCAL METHODOLOGIES AND THEIR APPLICATION TO NONLINEAR ANALYSIS
}

Ahmed K. Noor

George Washington University

NASA Langley Research Center

Hampton, Virginia

\begin{abstract}
An assessment is made of the potential of different global-local analysis strategies for predicting the nonlinear and postbuckling responses of structures. Two postbuckling problems of composite panels are used as benchmarks and the application of different global-local methodologies to these benchmarks is outlined. The key elements of each of the global-local strategies are discussed and future research areas needed to realize the full potential of global-local methodologies are identified.

\section{NOMENCLATURE}

$E_{L}, E_{T} \quad$ Elastic moduli of the individual layers in the

$G_{L T}, G_{T T}$

n

$\mathrm{L}_{1}, \mathrm{~L}_{2}$

$\mathrm{N}$

q

$\mathrm{R}$

$\mathrm{r}$

$\mathrm{U}$

$u_{\alpha}, w$

$\mathrm{x}_{\alpha}^{\alpha}, \mathrm{x}_{3}$

$\varepsilon_{\text {LT }}$

The range of the subscript $\alpha$ is 1,2 .
\end{abstract}

\section{INTRODUCTION}

Considerable progress has recently been made in computational mechanics which is manifested by the development of versatile and powerful finiteelement discretization methods, improved numerical algorithms and programming techniques (see, for example, BELYTSCHKO \& HUGHES [1983]; NOOR \& PILKEY [1983]; NOOR [1983]; LIU, BELYTSCHKO \& PARK [1984]; and KARDESTUNCER [1985]). Also, an explosive growth has taken place in computer technology. In particular, the introduction of large expensive computer systems, usually referred to as supersystems, such as CRAY X-MP, CDC CYBER 205 and Denelcor HEP1 has made possible new levels of sophistication in the modeling of complex structures which were not possible before (NOOR, STORAASLI \& FULTON [1984]). In spite of these advances the detailed stress analysis of complex structures is very time consuming and, therefore, is not economically feasible. To date the only realistic structural response simulations that have been obtained 
involve either simple structural configurations or components of complicated configurations. Prediction of the response of future complex structures such as those of flight vehicles is likely to require more sophisticated analysis models than has heretcfore been done. This is because of the requirements of high performance, light weight and economy and the associated stringent design criteria. Also, analysis may of necessity replace tests in some missioncritical areas.

Among the different analysis methodologies that have high potential for the accurate prediction of detailed stress distribution in structures without overtaxing the available computational resources are the global-local methodologies which are basically hybrid modeling and/or analysis techniques. In order to put these methodologies in proper perspective, a brief summary is given of the different approaches for reducing the cost and/or time for solving nonlinear problems. The efforts devoted to this activity can be grouped into three different levels.

The first level is modeling. Reductions in cost of analysis can be achieved by using simple models that capture major effects in the responses and by exploiting all the symmetries and quasi-symmetries in the problem (see NOOR \& PETERS [1985]; and NOOR, ANDERSEN \& TANNER [1985]).

The second level is that of computational strategies. Significant reductions in time can be achieved by incorporating the known physical behavior into the computational model of the structure and by using global-local methodologies in which different analysis methods and/or models are coupled for predicting the nonlinear response of the structure.

The third level is that of numerical algorithms. These include fast algorithms for solution of equations (e.g., multigrid methods, operator splitting techniques, dynamic relaxation, and element-by-element techniques -HACKBUSCH \& TROTTENBERG [1982]; UNDERWOOD [1983]; and HUGHES, RAEFSKY, MULLER, WINGET \& LEVIT [1984]); as well as the vectorized and parallel numerical algorithms for use on pipeline and parallel processors (SCHENDEL [1984]; MIKLOSKO \& KOTOV [1984]; and PADDON [1984]).

The present study deals with global-local methodologies which belong to the second category. Specifically, the objectives of this paper are:

1) To review and assess the potential of a number of different globallocal analysis strategies for predicting the nonlinear and postbuckling responses of structures

2) To identify the future directions for research required to realize their full potential

Discussion of global-local methodologies is primarily focused on nonlinear analysis of composite panels with discontinuities (e.g., stiffeners and cutouts). Two benchmark problems of composite cylindrical panels with cutouts typical of those used in modern aircraft structures are selected to provide a focus for the discussion. However, many of the conclusions apply to other complex structural configurations.

The paper is divided into three parts. The first part describes the two benchmark problems, identifies their major characteristics, and lists the difficulties encountered in analyzing them using conventional finite-element methods. In the second part of the paper four global-local analysis strategies are reviewed and the potential for using these strategies in analyzing the benchmark problems is assessed.

The third part of the paper identifies the items that pace the progress of global-local methodologies and their application to nonlinear analysis. These are the recommended future directions of research. 


\section{BENCHMARK PROBLEMS AND THEIR CHARACTERISTICS}

The two benchmark problems selected for this study are shown in Fig. 1. They are postbuckling problems of laminated composite cylindrical panels with central circular cutouts. The loading consists of applied axial end displacements. One of the panels is unstiffened and the other has discrete blade stiffeners. The two panels are generic examples of modern composite aircraft components for which postbuckling strength is desired in the presence of local discontinuities such as holes and cracked stiffeners. In the conventional finite-element approach the panels are modeled using twodimensional shell elements and the stiffeners are modeled using twodimensional plate elements. The unstiffened panel was analyzed using an inhouse research program. Shear-flexible mixed finite elements were used in the modeling (see NOOR \& ANDERSEN [1982]). Also, extensive numerical solutions to this problem using continuum-based shell elements are presented in STANLEY [1985] in which the imperfection sensitivity of the panel is assessed. The stiffened panel was analyzed using the EISI-EAL program and the analysis results are given in KNIGHT, GREENE \& STROUD [1985]. The characteristics of the finite-element models used in the present study and those used in KNIGHT, GREENE \& STROUD [1985] are summarized in Table 1. The response of both panels exhibits inversion symmetry, and therefore, only one half of each panel needs to be analyzed (see NOOR, MATHERS \& ANDERSON [1977]). The numbers between parentheses in Table 1 refer to the number of elements and degrees of freedom required for analyzing the full panel.

The response of the unstiffened panel is shown in Figs. 2 and 3. The postbuckling response of the panel exhibits a sudden drop in the loading due to delamination in the neighborhood of the cutout (see KNIGHT \& STARNES [1984]). Figure 2 shows plots of the total axial load versus axial and normal displacements up to the maximum load reached. For the range of loading considered, the results shown in Fig. 2 agree reasonably well with the experimental and numerical results presented in KNIGHT \& STARNES [1984].

Figure 3 shows normalized contour plots of the axial and normal displacements as well as the axial strains on the top and bottom surfaces. Note the high strain concentration at the cutout. A finer model near the cutout is required for the accurate prediction of the strain in that region. On the basis of the studies made, the following characteristics of the two benchmark problems can be identified:

1. The presence of discontinuities (cutouts and stiffeners) results in large numbers of degrees of freedom in the finite-element models.

2. The detailed stress analysis (including determination of interlaminar stresses) near the cutout requires either a higher order two-dimensional theory or a three-dimensional theory. Failure analysis (including prediction of delamination) requires even more sophistication in the modeling and analysis.

3. The postbuckling response exhibits large rotations in certain regions.

4. The postbuckling response of the unstiffened panel is highly sensitive to initial imperfections. Tracing the postbuckling response past the maximum load point requires the inclusion of initial imperfections in the model (see STANLEY [1985]).

\section{GLOBAL-LOCAL ANALYSIS STRATEGIES}

In this section, the application of four different global-local analysis 
strategies to the prediction of the nonlinear response of benchmark composite panels is discussed. In each case, the key features of the global-local approach and the requirements for its effective implementation are identified.

\subsection{Zooming Technique}

The first global-local approach considered is the zooming technique in which a global solution is obtained using a coarse grid. Then the detailed stress distribution near the cutout (local solution) is obtained by zooming on that area, refining the model, and using the displacements from the coarser model as input for the refined model (see Fig. 4). Single or multiple levels of zooming can be made corresponding to multiple passes from coarse to fine subdivisions (WILKINS [1983], and HIRAI, UCHIYAMA, MIZUTA \& PILKEY [1985]). Interelement compatibility can be maintained by either embedding the region of the fine grid into a superelement or by using transition elements at the interface between the coarse and the fine grids (ARMEN, Grumman Aircraft Systems, Bethpage, NY, Private Communication, 1985).

A number of questions remain in connection with this technique, namely:

1. Limitations of the technique for nonlinear problems

2. Criteria for selecting the extent of the region for refining the model and selection of the refined model

3. Treatment of the interfaces between the coarse and the fine grids and the effect of the error on the boundary data for the refined model on the accuracy of the stresses in that model

The early work on zooming techniques was based on heuristic and intuitive approaches for selecting the fine model. More recent work is based on the distribution of the strain energy density function. Currently, a variety of adaptive refinement techniques are available. Some of these techniques will be discussed in subsequent sections.

\subsection{Simultaneous Application of Two Discretization Techniques}

The early applications of this approach consisted of the simultaneous use of the finite-element method and the global (classical) variational technique (see MOTE [1971]). A variety of options are available depending on the extent of using each of the two techniques in the model (DONG [1983]). The concept has been later generalized to cover other techniques for the global (approximate) solution and the local (detailed) solution. A list of the common techniques used for generating these solutions is shown in Table 2.

The global solution can be obtained by using classical variational methods (e.g., Rayleigh-Ritz or weighted-residual approaches), or any of the discrete element methods (conventional finite elements, global elements, boundary element method) or their combinations. In the global (or macro) element method the structure is divided into a small number of elements and a suitable (usually nonpolynomial) approximation is made within each element. The continuity of the field variables across the interfaces is imposed implicitly in the variational functional (DELVES \& HALL [1979], and DELVES \& PHILLIPS [1980]). The global element method is a compromise between classical variational techniques and finite-element method. It combines the rapid convergence of global variational methods with the ability to handle complicated geometries.

The boundary element method is an effective technique for solution of linear and materially nonlinear structural problems with high stress gradients (or singularities). However, it is not competitive with either the finite- 
element or the global element method for geometrically nonlinear problems (see KAMIYA \& SAWAKI [1982]; and KAMIYA, SAWAKI \& NAKAMURA [1984]).

Among the different techniques for local analysis are the discrete element methods and analytical solutions (e.g., polar and/or edge functions PATTIBIRAMAN, RAMAMURTI \& REDDY [1974]). Figure 5 shows three different combinations of discrete element methods for analyzing the unstiffened composite panel.

The effective implementation of this global-local strategy requires:

a) criteria for selecting the proper global and local analysis techniques and

b) problem-adaptive strategies for generating global solutions and treatment of interfaces.

\subsection{Reduction Methods}

These are hybrid two-step techniques which are based on the successive application of a discrete element method (finite elements, boundary elements or combination of finite elements and boundary elements) and classical variational techniques (see, for example, NOOR [1982]; and NOOR \& PETERS [1983]). The discrete element method is used to generate few global approximation vectors (or modes). The classical variational technique is then used to compute the amplitudes of these modes. The primary objective of using reduction methods is to reduce considerably the number of degrees of freedom in the initial discretization, and hence, reduce the computational effort involved in the solution of the nonlinear problem.

The application of reduction methods to the unstiffened composite panel problem is depicted in Figs. 6 and 7. Figure 6 shows the accuracy of the normal displacements and total strain energy obtained by using four global approximation vectors (generated at zero loading). Figure 7 shows contours of the normal displacement $w$ of the first three global approximation vectors.

Two recent applications of reduction methods deserve further examination. In the first, only partial reduction is made. The degrees of freedom in the region of strong nonlinearity (e.g., near the cutout) are retained; the other degrees of freedom are reduced. In the second application, the response of a complex structure (e.g., stiffened panel) is generated using small (or large) perturbations from the response of a simpler system (e.g., unstiffened panel). It is also possible to use a hierarchy of simpler structural systems in generating the response of the original complex structure. This is accomplished by choosing a number of perturbation parameters, and successively applying a single-parameter reduction method with each of the parameters. Application of this strategy to the nonlinear analysis of anisotropic panels is described in NOOR [1985].

The wide acceptance of reduction methods and their incorporation into commercial programs requires: a) the selection of a simple set of global approximation vectors and $b$ ) the development of a problem-adaptive.strategy for error sensing and control.

3.4 Hierarchy of Mathematical Models and/or Numerical Approximation Techniques

The last global-local approach considered is that based on a hierarchy of mathematical models for different parts of the structure. The application of this approach to the stiffened composite panel is depicted in Fig. 8 where a heuristic choice is made of the mathematical models. For the panel a boundary-layer (or a higher order two-dimensional) theory is used near the 
cutout, followed by a first-order shear deformation theory, and then a classical shell theory. For the stiffeners, a plate theory is used near the cutout, followed by a thin-walled beam theory and then a shear deformation or a classical beam theory. The effective implementation of this approach requires the following:

1. Systematic procedure for generating the hierarchy of mathematical models (e.g., the method of initial functions of V. Z. Vlasov - VLASOV \& LEONTEV [1966]; and IYENGAR, CHANDRASHEKHARAN \& SEBASTIAN [1974]); or the asymptotic integration technique - GOLDENVEIZER [1976])

2. Criteria for the adaptive refinement of the mathematical model

3. Treatment of the interfaces between the different regions

\section{TREATMENT OF INTERFACES}

The treatment of interfaces is one of the key elements of the globallocal analysis. The two commonly used approaches for maintaining displacement compatibility and traction reciprocity at the interfaces are: 1) Lagrange multiplier method; and 2) penalty function method. The second approach has the advantage that it does not lead to any extra unknowns or equations (DELVES \& HALL [1979]). The numerical problem associated with increasing the penalty weight, to meet constraint satisfaction tolerances can be overcome by using the iterative procedure described in FELIPPA [1978].

\section{QUALITY CONTROL OF NUMERICAL SOLUTIONS}

One of the most difficult aspects of numerical modeling is the validation of the results and ensuring that a given model is adequate for the particular problem at hand. In general, there are three types of errors in the numerical solution. These errors are (see UTKU \& MELOSH [1984]):

1. Mathematical modeling errors, which result from the simplifications made in abstracting the mathematical model from the real structure.

2. Discretization errors, which are caused by the numerical discretization of the continuous mathematical model.

3. Manipulation exrors, which are caused by: a) the finite precision of the computers (limitation in representing real numbers due to the finiteness of the computer word length); and $b$ ) the errors resulting in the process of solving the equations of the discrete model (e.g., using iterative methods).

In this paper only the second type, namely: discretization errors, is considered. There are two classical approaches for estimating these errors (KELLY, GAGO \& ZIENKIEWICZ [1983]).

1. Extension methods - based on reanalysis of the structure on a sequence of meshes of increasing refinements (h extension); with a hierarchic set of interpolation polynomials ( $p$ extension); or using a combination of the two ( $h-p$ extension).

2. Dual (or complementary) procedure - based on obtaining two solutions with two different computer programs to provide bounds on global response characteristics.

Both of these approaches are too expensive for practical implementation.

In recent years, considerable effort has been devoted to the development of a posteriori error estimates that are based on information obtained during the solution process itself (KELLY, GAGO \& ZIENKIEWICZ [1983]; BABUSKA \& GUI [1985]; SZABO [1984]; and SPECHT [1984]). For structural mechanics problems, all these error estimates were developed for compatible displacement models. 
Among the error estimators developed to date are the following two:

1. Local energy norm error. This is the square root of the strain energy of the error. This is a local-global measure in the sense that it measures a global response characteristic, locally (within an individual element). In nonlinear problems, the measure can be used by linearization around a nonlinear solution and evaluating the energy norm of the linearized problem.

2. Interior and boundary residuals. These represent the equilibrium defects in the interior on the portion of the boundary where tractions are prescribed as well as the jumps in the tractions at interelement boundaries. For uniform grids with linear, bilinear and trilinear shape functions the contributions of the jumps dominate the residual and, therefore, the residual can be approximated by the traction jumps. A simple approximate method of evaluating these residuals for elements with hierarchic shape functions was given in KELLY, GAGO \& ZIENKIEWICZ [1983].

The error estimators, in addition to providing information about the quality of solutions, form the basis for adaptive improvement of the finiteelement solution. This can be accomplished by enriching or improving the approximation using one of the following approaches (or possibly, their combinations).

1. Refining the mesh

2. Moving the nodes (node relocation)

3. Increasing the local order of the approximation

4. Using the iterated defect correction method

The third approach has the advantages over the first two of being easy to implement and of providing a simple formula for the error estimator. The fourth approach is based on using the numerical solution obtained to construct a pseudo or neighboring problem whose exact solution is known (e.g., polynomial or spline interpolation of the discrete numerical solution). The pseudo problem is then solved using the same finite-element model as that used for the original problem. The error in the pseudo problem is assumed to be a close approximation of the error in the original problem and is used as a correction to that solution. The technique has been successfully applied to the numerical solution of stiff systems of ordinary differential equations and appears to have high potential for application to finite-element boundary value-problems (ZADUNAISKY [1976]; FRANK, HERTLING \& MONNET [1983]; and BOHMER \& STETTER [1984]).

\section{POSTPROCESSING AND STRESS CALCULATION}

In displacement finite-element models, the strain energy of the structure is the highest quality information that can be extracted from the finiteelement solution. The accuracy and rate of convergence of stresses depend on how (and where) they are computed. Several approaches have been suggested for improving the accuracy of stress calculations (see, for example, HINTON \& CAMPBELL [1974]; CAREY [1982]; ZIENKIEWICZ, XI-KUI \& NAKAZAWA [1985]; and BABUSKA \& MILLER [1984]). Among these are:

1. Evaluating the stresses at numerical quadrature points and determining their values at the nodes by extrapolation

2. Computing the stresses using the discarded structural equations (corresponding to prescribed displacement boundary conditions)

3. Averaging or smoothing based on projection techniques

4. Using influence function methods 
The first approach is by far the most commonly used. Superconvergence (increased accuracy and improved rates of convergence) has been observed for stresses evaluated at quadrature points. Note that the stresses cannot have a faster convergence than the strain energy. The second approach is particularly useful for evaluating the stresses at the boundaries. The third and fourth approaches improve the accuracy of stress predictions through the filtering of spurious oscillations. A systematic assessment of the latter two approaches is needed.

\section{FUTURE DIRECTIONS FOR RESEARCH}

Global-local analysis strategies have high potential for the reliable and efficient prediction of the nonlinear response of complex structures subjected to different loadings. To realize this potential the global-local strategy must include the following seven key elements:

1. Rational selection of a hierarchy of mathematical models for different parts of the structure and a strategy for the adaptive refinement of these models

2. Use of global (or macro) elements for discretization whenever appropriate with interface conditions satisfied via exterior penalty method

3. Use of reliable failure criteria and discrete elements that account for the progressive failure mechanisms

4. Application of operator splitting in conjunction with reduction method for generating the response of the complex structure by using large perturbations from the response of a simpler structure

5. Postprocessing to increase the accuracy of stress calculations

6. Quality control of numerical solutions

7. Exploiting the computational power of new multiprocessor machines through parallelization of the problem formulation, computational strategy as well as the numerical algorithms.

Each of the aforementioned key elements requires major development to reach the level of maturity needed for routine inclusion in the global-local strategy. To this end, there are pacing items that must be addressed by the research community. Among the items that pace the progress of global-local methodologies are the development of:

1. Criteria and control parameters for selecting the mathematical model, as well as adaptive strategies for refining the model whenever needed. Also, strategies for blending regions of different structural behavior (e.g., boundary layer, two/three dimensional models of the structure).

2. Reliable failure criteria and shell elements that account for the composite delamination mechanisms.

3. Simple and accurate techniques for stress calculations which provide the same accuracy as that of the strain energy.

4. Error estimation and adaptive improvement strategies. This is an area which requires more attention by researchers. In particular, error estimators that satisfy the following four criteria need to be developed for nonlinear analysis:

a) provide reliable local assessment of the error with extrapolation to global estimation

b) computationally inexpensive to evaluate

c) applicable to a wide class of discrete elements

d) easy to use in conjunction with adaptive improvement

5. Parallel computational strategies for multiprocessor computers. 
These strategies include the use of: a) primitive variables (e.g., threefield mixed formulation); b) domain decomposition (with minimization of interfaces); and c) operator splitting to uncouple the algebraic equations.

In addition, the intense research effort currently under way on parallel numerical algorithms (see, for example, NOOR [1983], and PADDON [1984]) should be brought to bear on global-local methodologies. Due to the wide variety of new parallel computers, the idea of developing macro algorithms which are efficient on different parallel machines should be investigated. The numerical tasks in these algorithms are performed by different programs which are optimized for each of the individual machines.

\section{CONCLUDING REMARKS}

A review and an assessment were made of global-local strategies for the nonlinear analysis of structures. To provide a focus for the discussion two benchmark problems of postbuckling of laminated composite cylindrical panels were selected. The major characteristics of these problems were identified.

A number of global-local analysis strategies were reviewed, their potential for solving the benchmark problems discussed and their shortcomings delineated. Also, error estimation and postprocessing techniques were reviewed.

The items that pace the progress of global-local methodologies are identified and are, therefore, recommended as future directions for research. These include the coupling of different global-local methodologies; postprocessing and stress calculation methods; quality control and adaptive improvement of numerical algorithms; and effective computational strategies for new computing systems.

\section{REFERENCES}

BABUSKA, I. \& MILLER, A. (1984), "The Postprocessing Approach in the Finite Element Method - Part 1: Calculation of Displacements, Stresses, and Other Higher Derivatives of the Displacements," International Journal for Numerical Methods in Engineering, Vol. 20, pp. 1085-1109.

BABUSKA, I. \& GUI, W. (1985), "Basic Principles of Feedback and Adaptive Approaches in the Finite Element Method," Technical Note BN-1042, Institute for Physical Science and Technology, University of Maryland.

BELYTSCHKO, T. \& HUGHES, T. J. R. (eds.) (1983), Computational Methods for Transient Analysis, North Holland Publishing Company.

BOHMER, K. \& STETTER, H. J. (eds.) (1984), Defect Correction Methods - Theory and Applications, Springer-Verlag.

CAREY, G. F. (1982), "Derivative Calculations From Finite Element Solutions," Computer Methods in Applied Mechanics and Engineering, Vol. 35, pp. 1-14.

DELVES, L. M. \& HALL, C. A. (1979), "An Implicit Matching Principle for Global Element Calculations," Journal of the Institute of Mathematics and Applications, Vol. 23, pp. 223-234. 
DELVES, L. M. \& PHILLIPS, C. (1980), "A Fast Implementation of the Global Element Method," Journal of the Institute of Mathematics and Its Applications, Vol. 25, pp. 177-197.

DONG, S. B. (1983), "Global-Local Finite Element Methods," in State-of-theArt Surveys on Finite Element Technology, ed. by A. K. Noor and W. D. Pilkey, American Society of Mechanical Engineers, pp. 451-474.

FELIPPA, C. A. (1978), "Iterative Procedures for Improving Penalty Function Solutions of Algebraic Systems," International Journal for Numerical Methods in Engineering, Vol. 12, pp. 821-836.

FRANK, R., HERTLING, J. \& MONNET, J. P. (1983), "The Application of Iterated Defect Correction to Variational Methods for Elliptic Boundary Value Problems," Computing, Vol. 30, pp. 121-135.

GOLDENVEIZER, A. L. (1976), Theory of Elastic Thin Shells, Nauka.

HACKBUSCH, W. \& TROTTENBERG, W. (eds.) (1982), Multigrid Methods, Lecture Notes in Mathematics No. 960. Proceedings of the conference held at Koln-Portz, Germany, Nov. 23-27, 1981, Springer-Verlag, Berlin.

HINTON, E. \& CAMPBELL, J. (1974), "Local and Global Smoothing of Discontinuous Finite Element Functions Using a Least Square Method," International Journal for Numerical Methods in Engineering, Vol. 8, pp. 461-480.

HIRAI, I., UCHIYAMA, Y., MIZUTA, Y. \& PILKEY, W. D. (1985), "An Exact Zooming Method," Finite Elements in Analysis and Design, Vol. 1, pp. 61-69.

HUGHES, T. J. R., RAEFSKY, A., MULLER, A., WINGET, J. \& LEVIT, I. (1984), "A Progress Report on EBE Solution Procedures in Solid Mechanics," Proceedings of the Second International Conference on Numerical Methods for Nonlinear Problems, Barcelona, Spain, April 9-13, 1984.

IYENGAR, K. T. S. R., CHANDRASHEKHARAN, K. \& SEBASTIAN, V. K. (1974), "On the Analysis of Thick Rectangular Plates," Ingenieur-Archiv, Vol. 43, pp. $317-330$.

KAMIYA, N. \& SAWAKI, Y. (1982), "An Integral Equation Approach to Finite Deflection of Elastic Plates," International Journal of Nonlinear Mechanics, Vol. 17, No. 3, pp. 187-194.

KAMIYA, N., SAWAKI, Y. \& NAKAMURA, Y. (1984), "Postbuckling Analysis by the Boundary Element Method," Engineering Analysis, Vol. 1, No. 1, pp. 40-44.

KARDESTUNCER, H. (ed.) (1985), Unification of Finite Element Software Systems, North-Holland Publishing Company.

KELLY, D. W., GAGO, J. P. de S. R. \& ZIENKIEWICZ, O. C. (1983), "A Posteriori Error Analysis and Adaptive Processes in the Finite Element Method: Part I - Error Analysis; Part II - Adaptive Mesh Refinement," International Journal for Numerical Methods in Engineering, Vol. 19, pp. 1593-1619 and 1621-1656. 
KNIGHT, N. F., GREENE, W. H. \& STROUD, W. J. (1985), "Nonl inear Response of a Blade-Stiffened Graphite-Epoxy Panel with a Discontinuous Stiffener: Work in Progress," Proceedings of the Workshop on Computational Methods of Structural Mechanics and Dynamics, NASA Langley Research Center, Hampton, VA, June 19-21, 1985.

KNIGHT, N. F. \& STARNES, J. H. (1984), "Postbuckling Behavior of Axially Compressed Graphite-Epoxy Cylindrical Panels with Circular Holes," in Collapse Analysis of Structures, ed. by L. H. Sobel and K. Thomas, PVP-Vol. 84, American Society of Mechanical Engineers, pp. 153-167.

LIU, W. K., BELYTSCHKO, T. \& PARK, K. C. (1984), Innovative Methods for Nonlinear Problems, Pineridge Press, Swansea, United Kingdom.

MIKLOSKO, J. \& KOTOV, V. E. (eds.) (1984), Algorithms, Software and Hardware of Parallel Computers, Springer-Verlag.

MOTE, C. D. (1971), "Global-Local Finite Element," International Journal for Numerical Methods in Engineering, Vol. 3, pp. 565-574.

NOOR, A. K. (1982), "On Making Large Nonlinear Problems Small," Computer Methods in Applied Mechanics and Engineering," Vol. 34, pp. 955-985.

NOOR, A. K. (ed.) (1983), Impact of New Computing Systems on Computational Mechanics, The American Society of Mechanical Engineers.

NOOR, A. K. (1985), "Reduction Method for the Nonlinear Analysis of Symmetric Anisotropic Panels," Proceedings of the Europe-U.S. Symposium on Finite Element Methods for Nonlinear Problems, Norwegian Institute of Technology, Trondheim, Norway, Aug. 12-15, 1985.

NOOR, A. K. \& ANDERSEN, C. M. (1982), "Mixed Models and Reduced/Selective Integration Displacement Models for Nonlinear Shell Analysis," International Journal for Numerical Methods in Engineering, Vol. 18, pp. 1429-1454.

NOOR, A. K. \& PETERS, J. M. (1983), "Recent Advances in Reduction Methods for Instability Analysis of Structures," Computers and Structures, Vol. 16, pp. 67-80.

NOOR, A. K. \& PETERS, J. M. (1985), "Model-Size Reduction Technique for the Analysis of Symmetric Anisotropic Structures," Engineering Computations, Vol. 2, No. 4, pp. 285-292.

NOOR, A. K. \& PILKEY, W. D. (eds.) (1983), State-of-the-Art Surveys on Finite Element Technology, The American Society of Mechanical Engineers.

NOOR, A. K., ANDERSEN, C. M. \& TANNER, J. A. (1985), "Exploiting Symmetries in the Modeling and Analysis of Tires, "Proceedings of the Workshop on Computational Methods of Structural Mechanics and Dynamics, NASA Langley Research Center, Hampton, Virginia, June 19-21, 1985. 
NOOR, A. K., MATHERS, M. D. \& ANDERSON, M. S. (1977), "Exploiting Symmetries for Efficient Postbuckling Analysis of Composite Plates," AIAA Journal, Vol. 15, No. 1, pp. 24-32.

NOOR, A. K., STORASSLI, O. O. \& FULTON, R. E. (1984), "Impact of New Computing Systems on Computational Mechanics and Flight Vehicle Structures Technology," AGARD Report No. 706.

PADDON, D. J. (ed.) (1984), Supercomputers and Parallel Computation, Clarendon Press, 0xford.

PATTIBIRAMAN, J., RAMAMURTI, V. \& REDDY, D. V. (1974), "Statics and Dynamics of Elastic Shells with Cutouts - A Review," Journal of Ship Research, Vol. 18, No. 2, pp. 113-126.

SCHENDEL, U. (1984), Introduction to Numerical Methods for Parallel Computers, E.llis Horwood, Ltd.

SPECHT, B. (1984), "A General Construction of Local Error Estimates for Conforming Finite Elements," Computers and Structures, Vol. 19, pp. 815-822.

STANley, G. M. (Aug. 1985), "Continuum-Based Shell Elements," Ph.D. Dissertation, Stanford University.

SZABO, B. A. (1984), "Estimation and Control of Error Based on p-Convergence," Proceedings of the International Conference on Accuracy Estimates and Adaptive Refinements in Finite Element Computations, Lisbon, Portugal, June 19-22, 1984.

UNDERWOOD, P. G. (1983), "Dynamic Relaxation - A Review," in Computational Methods for Transient Dynamic Analysis, ed. by T. Belytschko and T. J. R. Hughes, North Holland Publishing Company.

UTKU, S. \& MELOSH, R. J. (1984), "Solution Errors in Finite Element Analysis," Computers and Structures, Vol. 18, pp. 379-393.

Vlasov, V. Z. \& LEONTEV, U. N. (1966), "Beams, Plates and Shells on Elastic Foundations," NASA TT-F-357.

WILKINS, D. J. (1983), "A Preliminary Damage Tolerance Methodology for Composite Structures," in Failure Analysis and Mechanisms of Failure of Fibrous Composite Structures, NASA CP-2278, pp. 67-93.

ZADUNAISKY, P. E. (1976), "On the Estimation of Errors Propagated in the Numerical Integration of Ordinary Differential Equations, "Numer. Math., Vol. 27, pp. 21-39.

ZIENKIEWICZ, O. C., XI-KUI, L. \& NAKAZAWA, S. (1985), "Iterative Solution of Mixed Problems and the Stress Recovery Procedures," Communications in Applied Numerical Methods, Vol. 1, pp. 3-9. 
TABLE 1. CHARACTERISTICS OF THE FINITE-ELEMENT MODELS USED FOR THE BENCHMARK PROBLEMS

\begin{tabular}{|l|c|c|c|}
\hline & \multirow{2}{*}{ Unstiffened Panel } & \multicolumn{2}{|c|}{$\begin{array}{c}\text { Blade-Stiffened Panel } \\
\text { (Knight, Greene \& Stroud [1985]) }\end{array}$} \\
\cline { 2 - 4 } & & Mesh 1 & \\
\hline Type of Element & Mixed, 9-Noded & & \\
\hline $\begin{array}{l}\text { Number of } \\
\text { Elements }\end{array}$ & 66 & 188 & $(1088)$ \\
\hline $\begin{array}{l}\text { Number of Displace- } \\
\text { ment Degrees of } \\
\text { Freedom }\end{array}$ & 1338 & $(376)$ & Hybrid 4-Noded \\
\hline
\end{tabular}

TABLE 2. PARTIAL LIST OF THE COMMONLY USED TECHNIQUES FOR GLOBAL AND LOCAL ANALYSES

\begin{tabular}{|l|c|}
\hline GLOBAL (APPROXIMATE) ANALYSIS & LOCAL (DETAILED) ANALYSIS \\
\hline o Global variational methods & o Discrete element methods \\
o Discrete element methods & o Conventional finite elements \\
o Conventional finite elements & o Special elements \\
o Global element method & o Boundary element method \\
o Boundary element method & o Analytic solutions \\
\hline
\end{tabular}



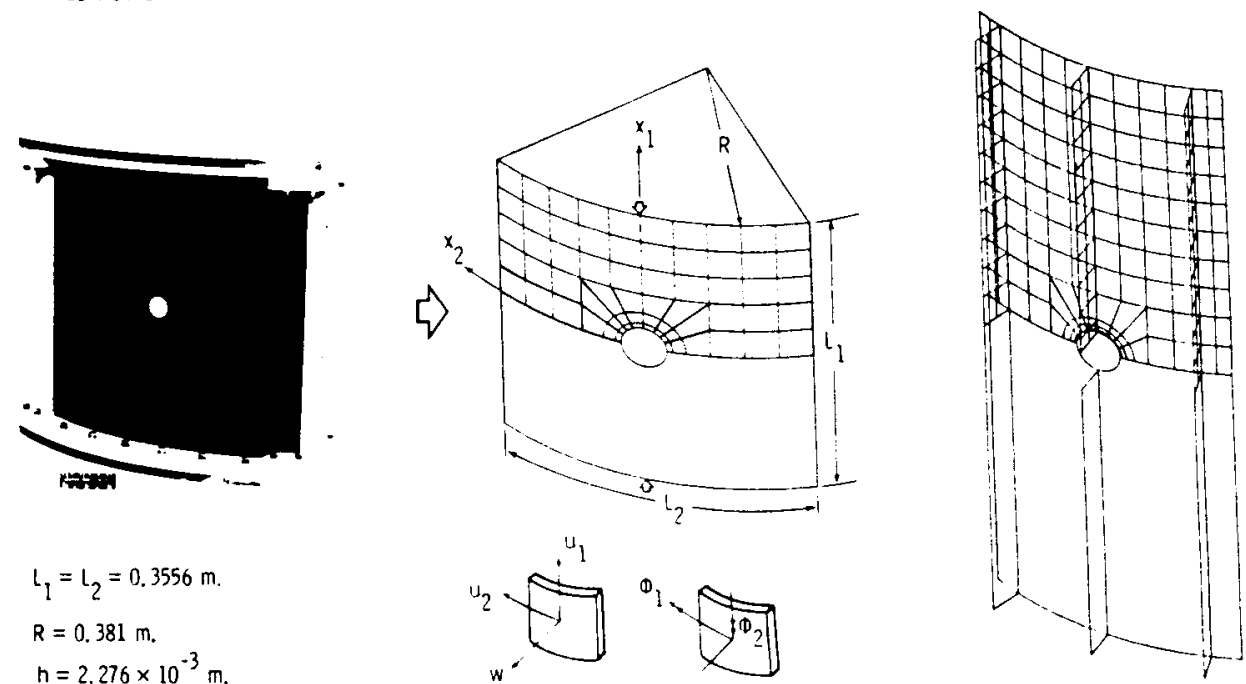

$L_{1}=L_{2}=0.3556 \mathrm{~m}$

$\mathrm{R}=0.381 \mathrm{~m}$

$h=2.276 \times 10^{-3} \mathrm{~m}$.

$E_{1}=1.31 \times 10^{11} \mathrm{~Pa}$

$E_{T}=1.303 \times 10^{10} \mathrm{~Pa}$

$G_{L T}=6.412 \times 10^{9} \mathrm{PJ}$

$G_{\pi}=5.102 \times 10^{9} \mathrm{~Pa}$

$u_{\text {IT }}=0.392$

Fiber orientation:

$[+45 / 90 / 0, / 90 / \mp 45]_{s}$

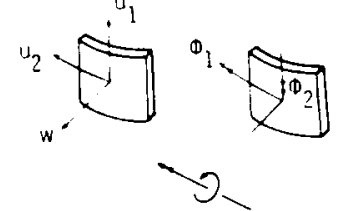

$\frac{25-P L Y \text { SKIN }}{1: 45 / 0_{2} /: 45 / 0_{3} /: 45 / 0_{3} / \cdot 45 / 0_{3} /: 45 / 0_{2} / \cdot 451 \mathrm{~T}}$

Boundary conditions

At $x_{1}= \pm L_{1} / 2$

$u_{1}=\mp q / 2, u_{2}=w=\Phi_{1}=\Phi_{2}=0$

24-PLY BLADES

At $x_{2}= \pm L_{2} / 2$

$w=\Phi_{1}=0$

Figure 1. Benchmark problems considered in present study.
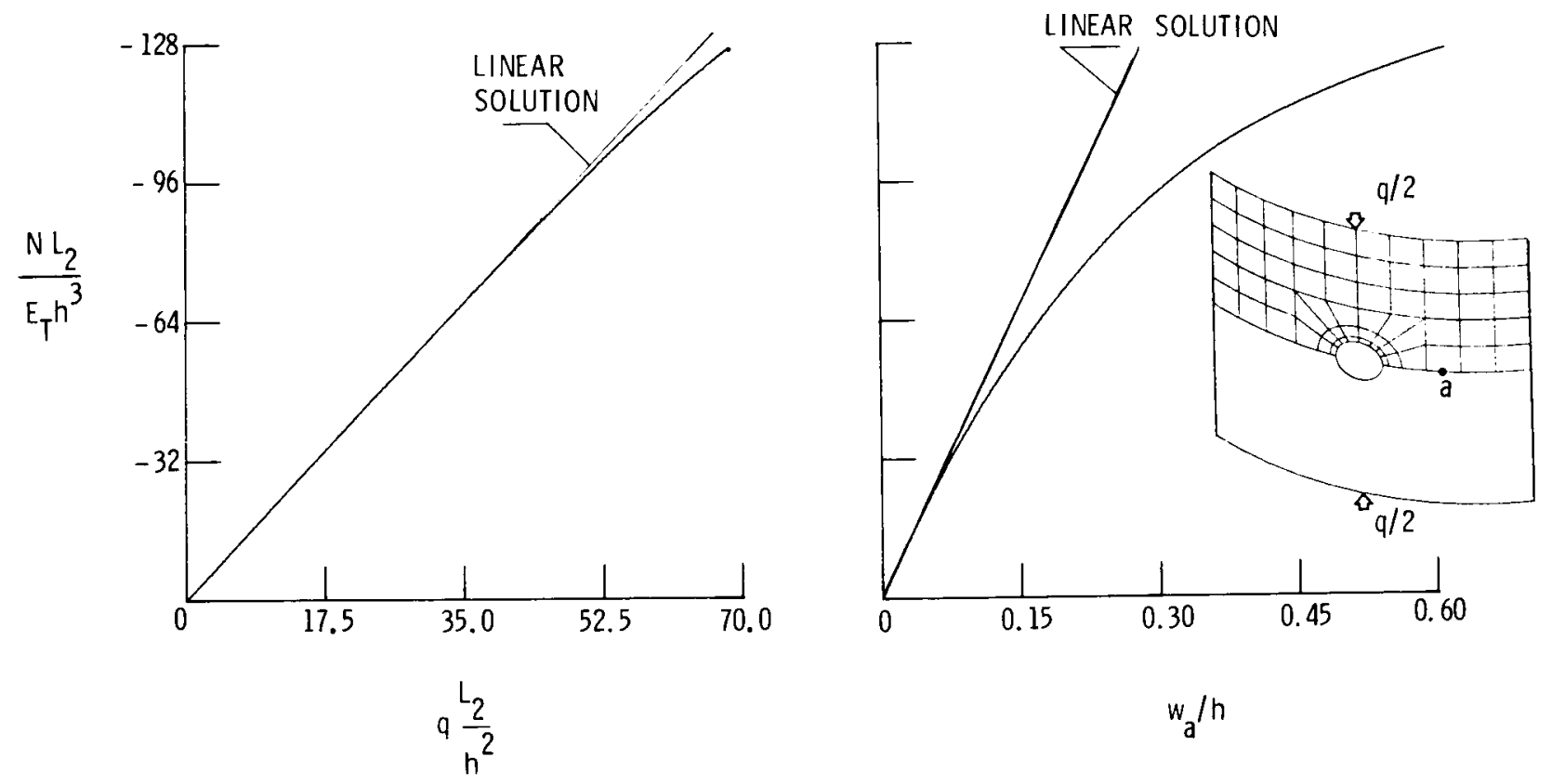

Figure 2. Nonlinear response of unstiffened panel subjected to end shortening (see fig. 1). 

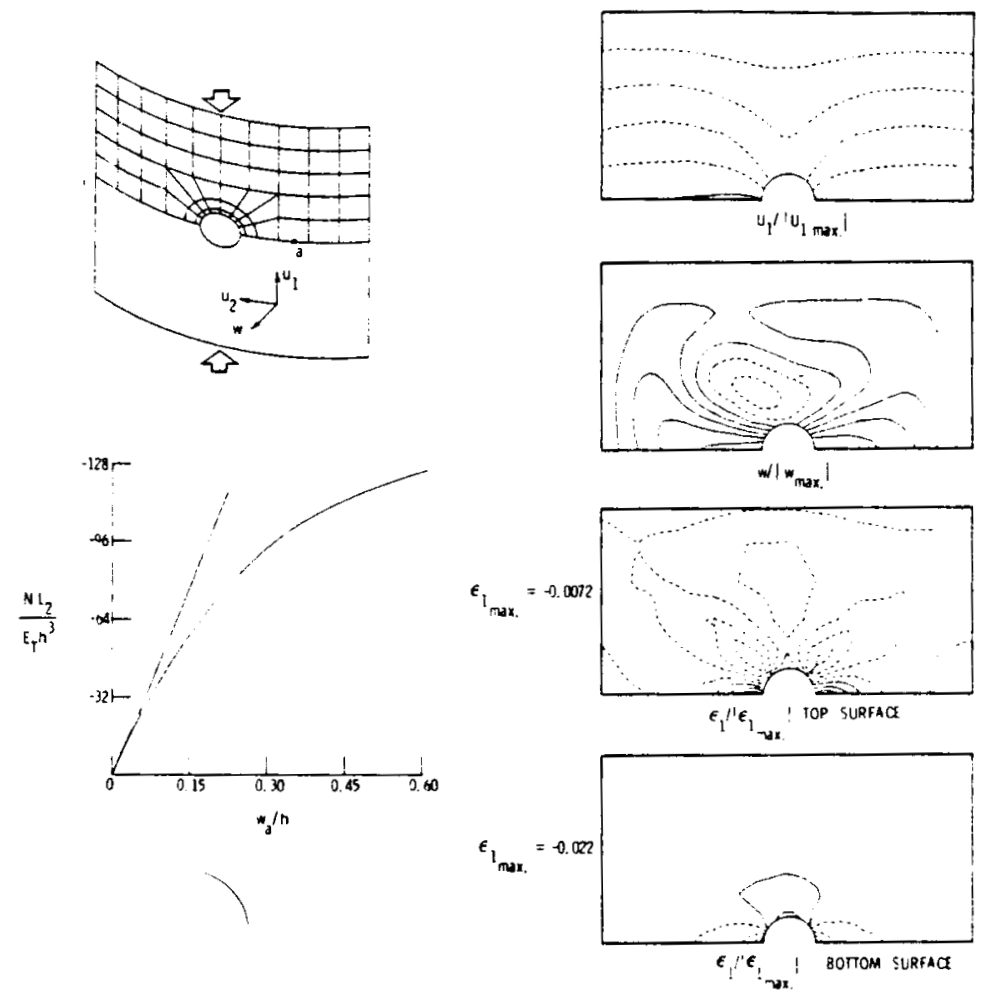

Figure 3. Normalized contour pilots for displacements and strains in untiffened panel at $\frac{\mathrm{NL}_{2}}{\mathrm{E}_{\mathrm{T}} \mathrm{h}^{3}}=126.6$
(see fig. 1).

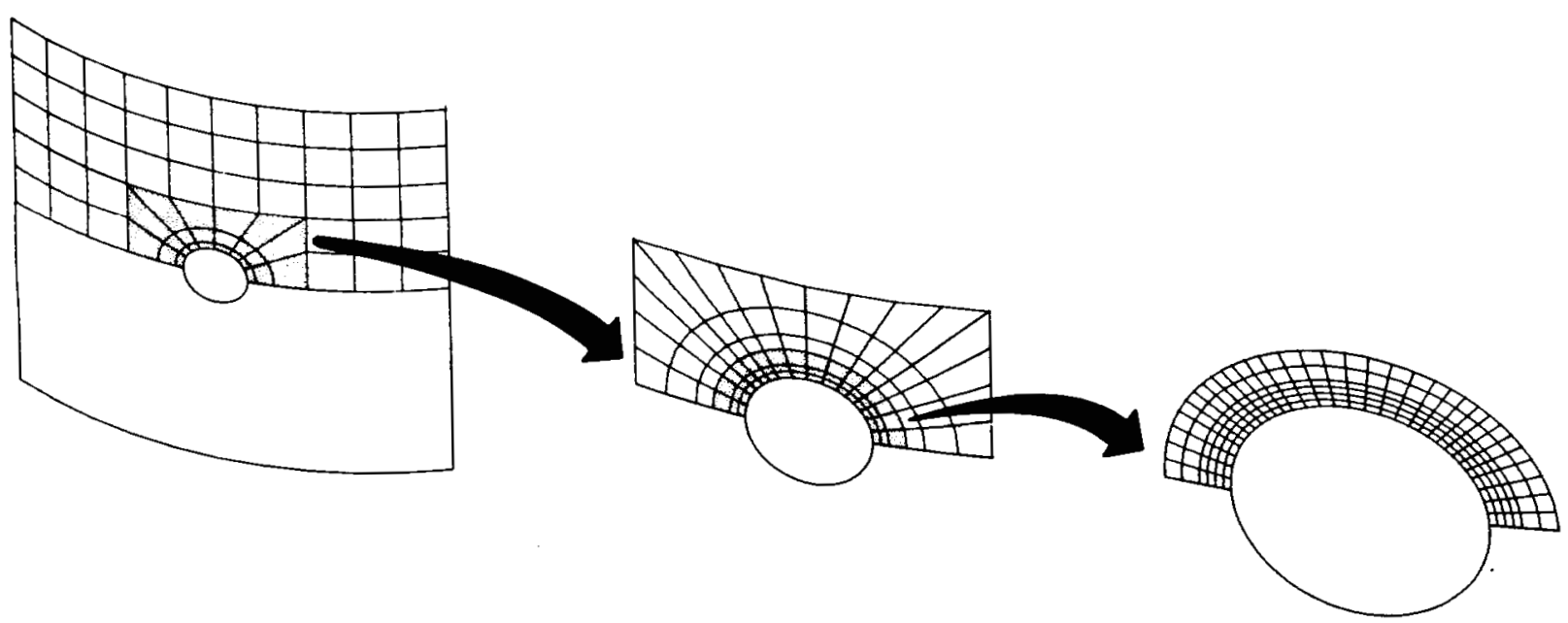

Figure 4. Application of zooming technique to unstiffened panel. 

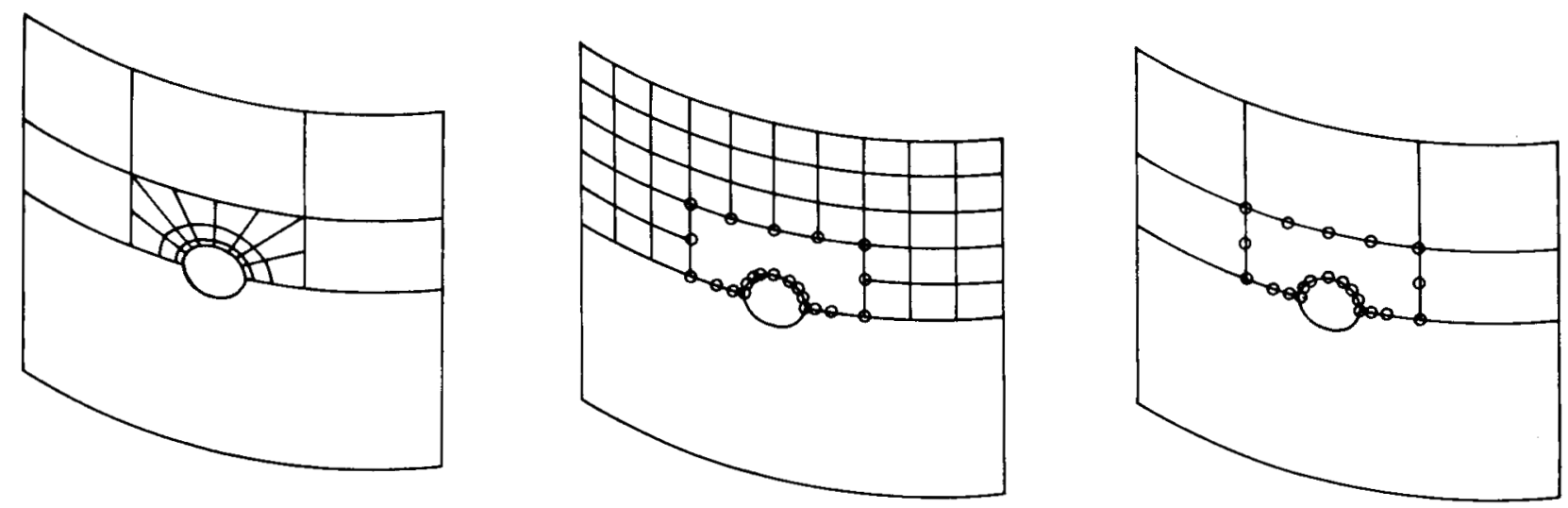

\begin{tabular}{|l|c|c|c|}
\hline $\begin{array}{l}\text { GLOBAL } \\
\text { ANALYSIS }\end{array}$ & GLOBAL ELEMENTS & CONVENTIONAL FINITE ELEMENTS & GLOBAL ELEMENTS \\
\hline $\begin{array}{l}\text { LOCAL } \\
\text { ANALYSIS }\end{array}$ & $\begin{array}{l}\text { CONVENTIONAL (OR SPECIAL) } \\
\text { FINITE ELEMENTS }\end{array}$ & BOUNDARY ELEMENTS & BOUNDARY ELEMENTS \\
\hline
\end{tabular}

Figure 5. Simultaneous application of two discrete element methods to the analysis of unstiffened panel.
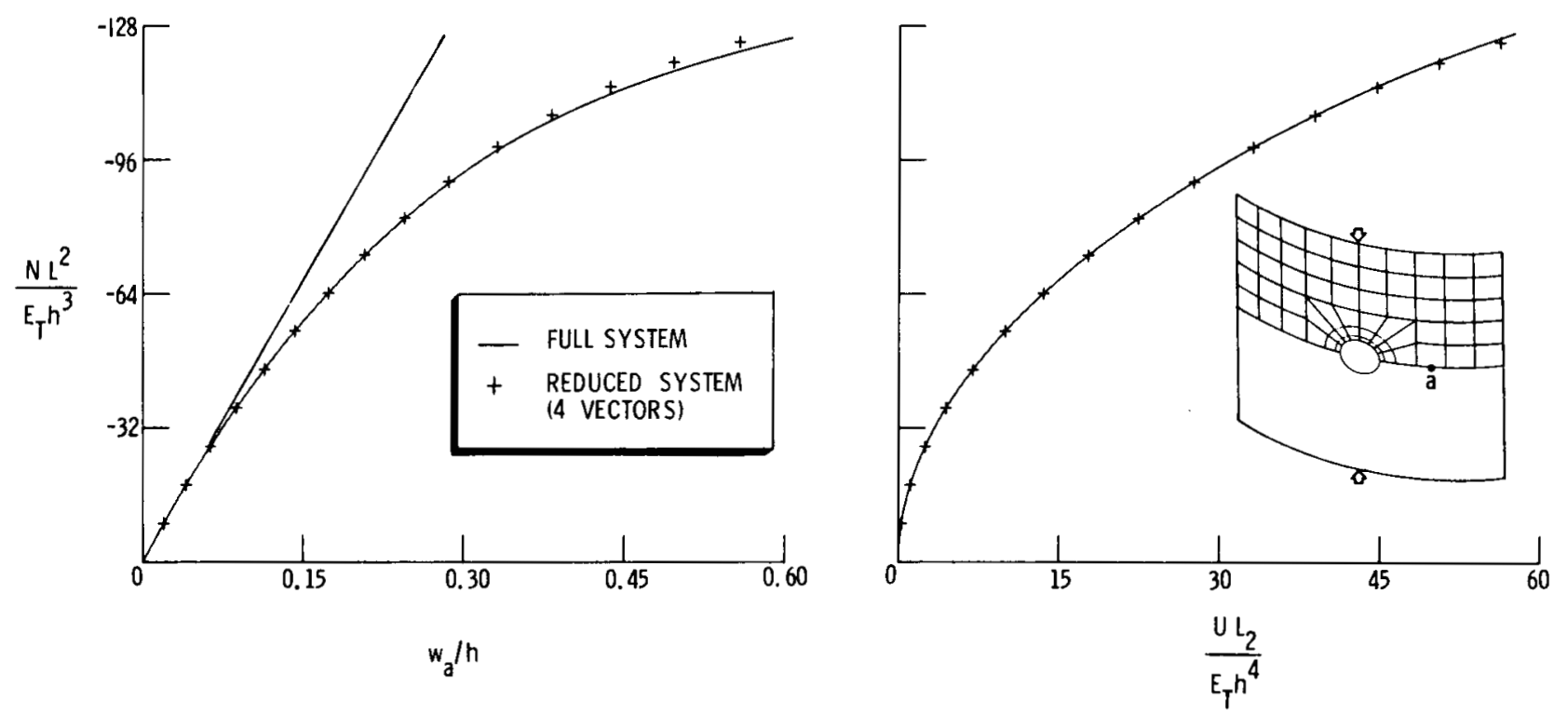

Figure 6. Accuracy of normal displacement $W$ and total strain energy $U$ obtained by reduction method. Unstiffened panel subjected to axial end shortening (see fig. 1). 

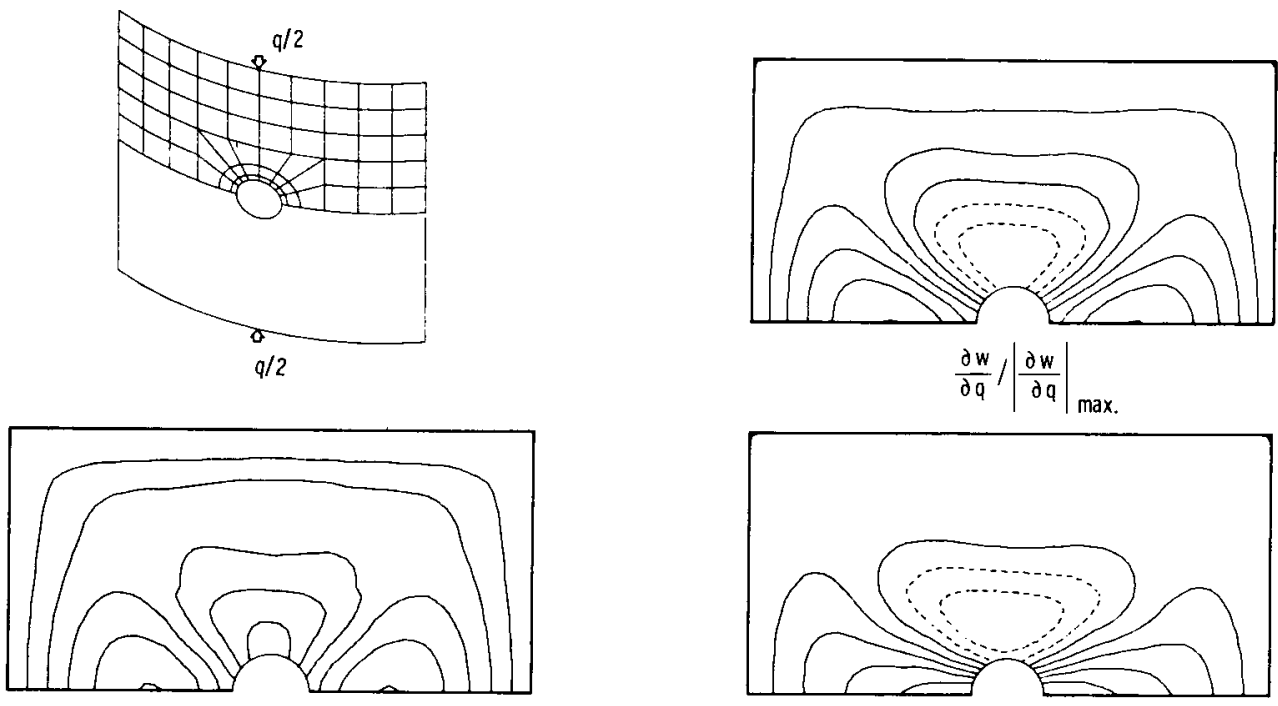

$\frac{\partial^{2} w}{\partial q^{2}} /\left|\frac{\partial^{2} w}{\partial q^{2}}\right|_{\text {max. }}$

$\frac{\partial^{3} w}{\partial q^{3}} f\left|\frac{\partial^{3} w}{\partial q^{3}}\right|_{\max .}$

Figure 7. Normalized contour plots for the global approximation vectors - unstiffened panel subjected to axial end shortening (see fig. 1).

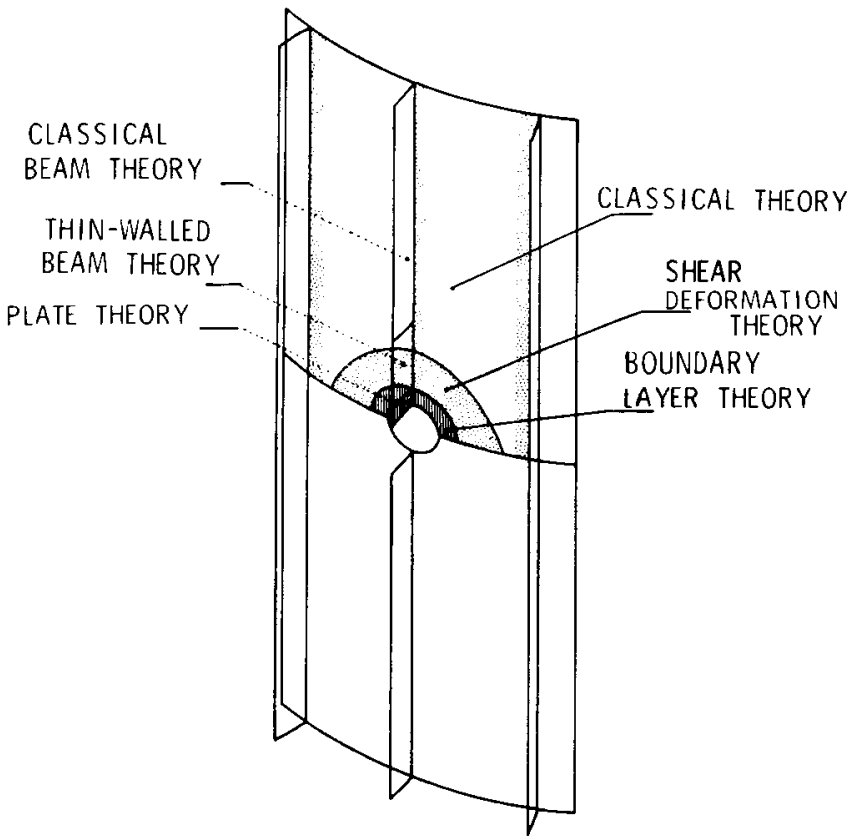

Figure 8. Heuristic approach for selecting a hierarchy of mathematical models for blade stiffened panel. 